\title{
Returning to Graduate School: Expectations of Success, Values of the Degree, and Managing the Costs
}

\author{
Diane L. Peters ${ }^{a}$ and Shanna R. Daly \\ ${ }^{a}$ LMSNorth America, ${ }^{b}$ University of Michigan
}

\begin{abstract}
Background Limited research exists on the experiences of engineering returners - those with undergraduate degrees who work for at least five years and return to academia for graduate degrees. Returners bring a different perspective to their graduate studies and postgraduate work than direct-pathway students but face additional challenges.
\end{abstract}

Purpose Our aim was to understand practitioners' decisions to return to graduate school and complete graduate degrees. Guided by expectancy value theory, we investigated their beliefs about their ability to succeed; the interest, attainment, and utility values returners placed on graduate school; the costs they experienced in returning; and the personal, programmatic, and cultural factors that mitigated these costs.

Design/Method We employed a qualitative interpretivist approach to investigate the returning experience through semi-structured interviews with 10 returners. We analyzed the results deductively, using expectancy value theory to understand participants' expectations of success and the values of those experiences, and inductively, to understand the types of costs that influenced the decision to return and complete graduate school.

Results Utility value drove participants' decisions to return and complete graduate programs, and participants had a high expectancy of success in earning their graduate degrees. Four types of costs emerged from analysis of the interviews: intellectual, balance, cultural and environmental, and financial. Participants employed various strategies to mitigate these costs.

Conclusions With the results of our study, potential returners can more effectively plan for success in the graduate environment, and universities can develop initiatives to better recruit returners and support their success.

Keywords returning students; expectancy value theory; motivation; graduate education

\section{Introduction}

Returners are those with undergraduate degrees who work outside of academia for at least five years and come back, either part- or full-time, to the academic setting to earn a graduate degree. Direct-pathway students proceed directly as undergraduates to graduate school, without taking any significant break in their education. Direct-pathway students are in the majority in science, technology, engineering, and mathematics (STEM) fields, particularly in doctoral programs. No nationally available statistics indicate how many practicing engineers return to earn a graduate degree; but age at graduation in various disciplines provides some 
indication of how the returner population in engineering compares with other fields. According to the 2009 Survey of Earned Doctorates (NSF, NIH, USED, USDA, NEH, \& NASE, 2009), the average age at graduation was 30.5 for engineering doctorates, 30.2 for physical science doctorates, and 31.3 for life science doctorates, compared with 34.5 for humanities and 40.5 for education. Local data from a research university revealed that, of approximately 1000 engineering $\mathrm{PhD}$ students, 170 had at least five years between their undergraduate degree and beginning of a $\mathrm{PhD}$ program (University of Michigan, 2011). While returning can be a challenging experience, it is not an uncommon pathway.

On the basis of these data, as well as Feagin's (1984) definition of minority groups, which includes physical or cultural traits that set a group apart and a shared sense of collective identity and common burdens, we consider returners, who are diverse in age, to be a minority in engineering graduate programs. Returners face challenges similar to other gender, racial, and ethnic minority groups (Howard-Hamilton, Morelon-Quainoo, Johson, Winkle-Wagner, \& Santiague, 2009; Pascarella \& Terenzini, 1991; Seymour \& Hewitt, 1997). While they are a minority in engineering graduate education, returners are an important group to study: (1) they represent alternative pathways to and through engineering graduate school, (2) they increase the diversity in graduate education programs, (3) their perspectives differ from those of direct-pathway students, and (4) they often directly apply their research results. These four points are elaborated on in the following paragraphs.

The National Science Foundation emphasizes the need for diverse pathways to and through engineering programs, including advanced degrees (NSF, 2012). Highly trained engineers are necessary to meet the demands of a competitive global economy (Baker, Tancred, \& Whitesides, 2002). Women and underrepresented groups decide not to pursue advanced degrees more often than do men and traditionally represented groups, thus depriving the profession of a diversity of highly trained engineers (Baker et al., 2002; Chubin, May, \& Babco, 2005; Selby, 1999). These groups may choose to return if this option is readily available to them, thus increasing the range of experiences represented in the graduate student community. Diverse teams can enhance problem-solving capacity and creativity (Hennessey \& Amabile, 1998) and develop innovations (Bassett-Jones, 2005; Hennessey \& Amabile, 1998; Iles \& Hayers, 1997; Latimer, 1998; Richard \& Shelor, 2002). Studying returners provides the foundation for supporting returners' pursuit of graduate degrees, and increased support for returners could increase the number of degrees they earn, thus providing more pathways to and through graduate engineering programs.

Returners are also important to study because they bring a different perspective to their work as graduate students and beyond, whether in academia, industry, or government. They have a variety of career and life experiences that inform their perspectives, and these perspectives could be the foundation of innovative outcomes to the world's complex problems. The combinations and connections of ideas from various contexts, such as work as a practitioner and the university setting, are often the sources of creative outcomes (Finke, Ward, \& Smith, 1992). Additionally, whether returners go back to industry or government or pursue an academic career upon earning their graduate degrees, the applications of their research to the engineering community are likely to be more immediate and direct. In industry or government, they will not have to acclimate to life as a practitioner and will not have to make their way through the ranks in the same way that direct-pathway students often do. In academia, they will already have knowledge of real-world applications to contextualize their work. In our case study, we found that the research of one returner addressed needs she had 
seen in industry, and the next steps after her $\mathrm{PhD}$ included direct initiatives related to the outcomes of this research (Peters \& Daly, 2011).

While there are many benefits to the presence of returners in the graduate student population, they have special needs that are not usually accommodated by graduate programs accustomed to direct-pathway students, and these unmet needs are factors that deter them from pursuing a graduate degree. By not addressing these needs, universities further the impression that a student must decide to get an engineering graduate degree while an undergraduate, and that the sacrifices in going back to school after working as a practitioner are too great. There is little research about the experiences of engineering returners, nor is there research to guide universities in utilizing engineering returners' knowledge and skills. Thus, our research aims to address these gaps and provide the basis for developing appropriate programs and resources for universities to attract returners and to support their success.

\section{Background}

There is limited research on engineering returners, including who they are, why they come back, and their experiences. However, research exists more broadly on returners across degree type and program, including research on adult students in both undergraduate and graduate programs across disciplines, the experiences of underrepresented groups (we identify returners as an underrepresented group), and adult education (Knowles, 1980). Thus, we combine all of these research areas to contribute to our foundational understanding of the returner experience in engineering.

The field of andragogy (education for adults) was developed based on the principles that adult education should differ from traditional education in several ways: (1) adults need to know the reason for learning something, (2) adults use prior experiences as their foundation for future learning, (3) adults need decision-making power in their education, (4) adults are motivated to learn subjects that are most directly relevant to their work, (5) adult learning is driven by solving problems rather than covering content, and (6) adult learning is driven more by internal motivation than external motivation (Knowles, 1980). These principles suggest key areas where returners may be dissatisfied with the graduate experience as well as ways graduate education should be shaped to provide satisfaction to returners.

Returning students differ from direct-pathway students in a number of ways. They are often more motivated and mature (Hofinger \& Feldmann, 2001; Prusak, 1999), more goaldirected (MacFagden, 2008; Prusak, 1999), and more aware of ethical issues (Hofinger \& Feldmann, 2001). They have better teamwork skills (Hofinger \& Feldmann, 2001), honed through daily practice in the workforce, and typically have a strong work ethic (Prusak, 1999). In many cases, they are more skilled with various tools and types of equipment (Prusak, 1999). They manage their time more effectively than younger students, and model effective study strategies for direct-pathway students to emulate (Richardson \& King, 1998). These characteristics can enrich the graduate experience for all students (Hofinger \& Feldmann, 2001; Prusak, 1999). Returners have many strengths, but they also face obstacles that graduate programs must help them overcome. We discuss needs related to the decision to return, admissions, and degree completion.

\section{Decision to Return and Admissions}

Returners lack information and mentoring as they make decisions about transitioning from practitioners to graduate students, since they often do not have direct and continuing access 
to professors, academic advisors, and university resources. In an earlier study, we investigated three engineering returners' perspectives on their experience of returning (Peters \& Daly, 2011). Emerging themes about their experience highlighted the importance of mentors, colleagues, university faculty, and role models in the decision to return to graduate school.

Returners also have difficulties determining how to finance their education. Unlike direct-pathway students, they may have significant financial obligations, including financial support of their families, mortgages, and other debts, and older graduate students are less likely than direct-pathway students to receive fellowships and teaching and research assistantships (Nettles \& Millett, 2006).

Returners may find it difficult to represent their skills well in traditional graduate school applications. It has been found, for example, that for women over age 24, the GRE underestimates academic success (Purdy \& Washburn, 2005). Thus, a returner with an average or low GRE score who has had success as an engineering practitioner could be overlooked by graduate engineering programs that rely heavily on GRE scores for admission.

\section{Degree Completion}

While returners are often skilled with industrial equipment, they may be less skilled with computers than direct-pathway students, and they may be out of practice in some of their math skills (Peters \& Daly, 2011; Prusak, 1999). Their preferred working style may not match well with that of their fellow direct-pathway students (Schilling, 2008), and they have reported struggling to develop successful team relationships with fellow graduate students (Peters \& Daly, 2011). Since teaching approaches in graduate programs affect student satisfaction (Conrad, Haworth, \& Millar, 1993), they should align with the returners' learning approaches if students are to be satisfied and complete their programs. The importance of aligning teaching and learning approaches is also consistent with the principles of andragogy because adults have specific learning motivators that best contribute to their success (Knowles, 1980).

Returners may also find they are not respected for the expertise they have developed as practitioners. One study found that engineering practitioners pursuing a doctorate in engineering education were frustrated because they felt their past experiences were not valued, and that their professors were not interested in their industry experiences and related skills and knowledge (Strutz, Cawthorne, Ferguson, Carnes, \& Ohland, 2011). This lack of interest in students' prior experience can affect their ability to use this prior experience as a foundation for their learning.

Returners report challenges in balancing personal and family responsibilities and other life obligations that younger students are less likely to have (Peters \& Daly, 2011), such as raising and caring for children and aging parents. Engineering graduate students with children are more likely to drop out and, if they stay, to take longer to complete their program than direct-pathway students (Nettles \& Millett, 2006). These factors make returners feel they do not "fit in" with younger students, causing them to feel less at home in the academic community and hampering their ability to successfully complete their graduate programs (Gardner, 2008; MacFagden, 2008).

\section{Research Framework}

Expectancy value theory (EVT) explains how and why people make choices on the basis of their expected results, the costs to make the choice, and their own interests and values. This 
theory explains why people choose a particular pathway when they have multiple options available to them, and what factors may prevent them from taking this pathway.

According to EVT, behavior is a function of one's competence belief (expectation of one's ability to achieve a goal) and the value placed on achieving that goal (Eccles, Barber, Updegraff, \& O'Brien, 1998; Fishbein \& Ajzen, 1972). The expectation of success and value placed on a goal are a function of a number of factors, including past experiences, personal identity beliefs, social influences (parents, friends, culture), and collective identity beliefs (aspects that tie individuals together; Eccles, 2005, 2009; Eccles et al., 1998). There are four types of values: interest - the individual's anticipated enjoyment of engaging in the activity; attainment - the individual's perception of how the activity contributes to the conception of who he or she is fundamentally; utility - the individual's perception of the advantages that will result from achieving the goal; and cost - the individual's perception of the required sacrifices, including effort, time, and psychological impact (Eccles, 2005, 2009; Wigfield \& Eccles, 2000).

Expectancy value theory has been widely used to explain how people make decisions in a variety of situations. It has been successfully applied to those in early childhood (Fredricks \& Eccles, 2002), adolescence (Boe, Henriksen, Lyons, \& Schreiner, 2011; Nagy, Trautwein, Baumert, Koller, \& Garrett, 2006), and adulthood (Matusovich, Streveler, Loshbaugh, Miller, \& Olds, 2008; Matusovich, Streveler, \& Miller, 2010). The EVT lens has provided insight on gender-specific choices (Ceci \& Williams, 2007; Frome, Alfeld, Eccles, \& Barber, 2006; Battle \& Wigfield, 2003), student course choices (Nagy et al., 2006), and student career choices (Frome et al., 2006; Matusovich et al., 2008). In particular, Matusovich et al. (2008) demonstrated the effectiveness of EVT in explaining student decisions to persist in earning an undergraduate engineering degree. In this article, we apply EVT to study persistence of returners toward a graduate degree.

\section{Research Design}

\section{Research Questions}

Guided by EVT, our work focused on the beliefs returners had about their ability to succeed; the interest, attainment, and utility values returners placed on the returning experience; the costs they experienced in returning; and the personal, programmatic, and cultural factors that mitigated these costs. Our work was guided by the following research questions: What expectations do returners have for their success in earning a graduate degree? What values motivate returners' decisions to earn a graduate degree? What costs do returners experience in returning? What factors mitigate the costs of returning?

\section{Participants}

To explore the returning experience in detail, we collected data from 10 returners; this sample size is consistent with the standards of detailed qualitative work (Patton, 2002; Van Note Chism, Douglas, \& Hilson, 2008). Recruitment was guided by diversity in background, experience, and years in the workforce, and also depended on the networking channels of the researchers. We focused on returners in engineering, but we also included several participants whose backgrounds or graduate interests were in a different STEM field. We expected that their experiences would be comparable to those who had bachelor's degrees in engineering and were also working on a graduate degree in engineering. While this was our rationale for including them as participants, our data collection and analysis procedure 
Table 1 Demographic Data for Study Participants

\begin{tabular}{|c|c|c|c|c|c|}
\hline Pseudonym & Gender & Age & $\begin{array}{l}\text { Gap } \\
\text { years }\end{array}$ & Current status & Graduate field of study \\
\hline Andrew & Male & 33 & 7 & Third year PhD student & Mechanical engineering \\
\hline Brenda & Female & 38 & 5 & Post-doctoral researcher & $\begin{array}{l}\text { Applied physics and } \\
\text { engineering }\end{array}$ \\
\hline Catherine & Female & 41 & 18 & First year $\mathrm{PhD}$ student & Design \\
\hline Danielle & Female & 45 & 15 & Recently finished $\mathrm{PhD}$ & Electrical engineering \\
\hline Evan & Male & 29 & 5 & Second year PhD student & Mechanical engineering \\
\hline Felicia & Female & 30 & 6 & Third year master's student & Biomedical engineering \\
\hline Gary & Male & 27 & 5 & First year master's student & Computer engineering \\
\hline Harald & Male & 26 & 5 & First year $\mathrm{PhD}$ student & Chemistry \\
\hline Ian & Male & 30 & 8 & First year master's student & Aerospace engineering \\
\hline John & Male & 28 & 6 & First year $\mathrm{PhD}$ student & Mechanical engineering \\
\hline
\end{tabular}

allowed us to determine if there were key differences related to disciplinary background or graduate program.

Participants were six males and four females, who ranged in age (26 to 45 years) and type of work experience (industry and government), and were in various stages of their graduate career. They also varied in length of time as practitioners, which we refer to as "gap years." Participants were all at the same institution, which was a research-focused university. Demographic data for participants is given in Table 1 . Actual names are replaced by pseudonyms in accordance with the IRB approval we obtained for this study.

Figure 1 presents the disciplinary background, type of work experience, and future plans upon graduation for each participant. Participants' key previous work and educational experiences correspond to the number of years they were engaged in those activities.

\section{Data Collection}

Data were collected using semi-structured interviews organized by key topics to discuss in the interview (Lindlof \& Taylor, 2002). The interview began by explaining logistics and gathering background information about the participant's demographics, education, and path between undergraduate and graduate school. The questions then focused on motivations for returning and the participant's preparations to do so. The remainder of the interview had the participant describe what it was like to be a returner, and included questions about the intellectual, academic, and social challenges they faced, as well as the strategies they employed to minimize those challenges. Because the interview was semi-structured, follow-up questions were asked throughout to clarify information, request further description, and probe more deeply into the participant's perspective on the experience. Table 2 presents an overview of the flow and key topics of the interview, with sample questions included. For the full interview protocol, see Peters and Daly (2011). Interviews lasted approximately one hour. They were audio recorded, and a transcript was produced after the completion of each interview.

\section{Data Analysis}

Data analysis began with deductive coding of each of the transcribed interviews, meaning thematic categories were pre-identified (Fereday \& Muir-Cochrane, 2006). In each of the interview transcripts, we highlighted aspects of each participant's responses as an indication 


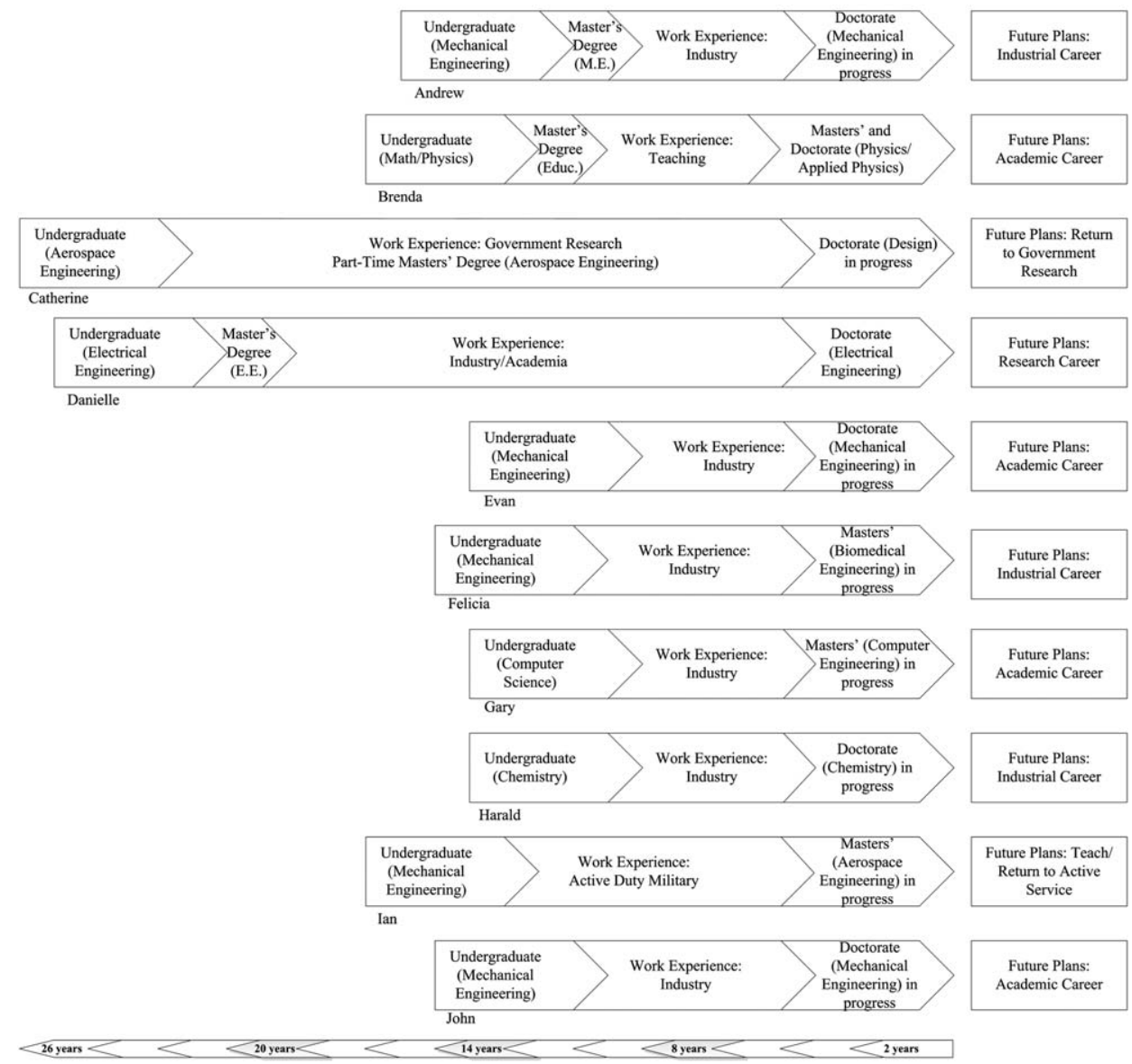

Figure 1 Disciplinary background, type of work experience, and future plans upon graduation for each participant. Participants' key previous work and educational experiences correspond to the number of years they were engaged in those activities

of their expectancy of success and the types of value they placed on the returning experience (interest, attainment, utility, and cost), based on the EVT framework and related definitions discussed in the Research Framework section above. A description of the codes is given in Table 3.

Once they decided to return and began their studies, the returners in our sample did not have significant doubts about their ability to complete the program (data to support this claim is presented in the Results section). Instead, their struggles in deciding to return and the doubts they had about completing the program were related to the value they placed on the outcome and, more specifically, the costs they associated with earning their graduate degrees. Thus, we coded for type of cost using an inductive approach: we developed codes bottom-up from the data based on emergent patterns (Patton, 2002; Thomas, 2006). These 
Table 2 Protocol Outline by Interview Segments

Topics covered Sample questions or statement

Opening statement

Logistics of interview session

Purpose of interview

Demographic and prior experience information Age

Time passed between undergrad and graduate school

Previous and current education program

Preparation for graduate return

Decision to return

Goals for returning

Choosing a program

Advice on returning

Returning experiences

Description of the experience

Differences between undergrad education experience

and gradate education experience

Challenges of returning

Description of program challenges with contextual examples

Description of personal challenges with contextual examples

Strategies for success

Strategies for challenges in the context of examples

Contributions to success
Our conversation will be recorded and later transcribed.

Everything you tell me will be confidential.

How many years passed between the time you received your bachelor's degree and the time you returned to school?

What were your undergraduate and graduate programs?

Work experience

Tell me about your decision to return to school for a graduate degree

Can you walk me through your choice of a program and school?

What kind of advice did you receive on your decision?

In what ways are you different from younger students?

What do you feel you have in common with younger students?

Can you tell me about a particular academic challenge you faced on returning to school?

Can you tell me about a particular social challenge you faced as a returning student?

Were there particular programs or initiatives at your school that contributed to your success?

Tell me about some of the strategies you used to deal with challenges.

patterns were identified by searching for repetition, specifically by identifying repetitions of key words and phrases, and of ideas expressed in different words (Ryan \& Bernard, 2003). This search was completed within a single interview and within the full set of interviews. The coding also focused on identifying things that differed between one interview and the next, in order to draw distinctions between the codes and the larger categories. (These codes and their descriptions are presented in Table 5).

Additionally, in our analysis of types of costs, we discovered that we could connect the types of costs returners experienced with the strategies they used to mitigate the cost. We used a modified version of the cost categories to represent the cost reduction and mitigation strategies that returners employed.

In our coding of the interest, attainment, and utility values participants perceived about the returning experience, we recognized differences in the emphases participants gave to each type of value. Thus, we also analyzed each transcript for the importance of each value type by considering the relative amount of discussion about it. Within each transcript, the 
Table 3 Deductive Codes Used in Data Analysis

\begin{tabular}{ll}
\hline \multicolumn{1}{c}{ Code } & Description \\
\hline Expectancy & $\begin{array}{c}\text { Returners indicate a belief or disbelief in their ability to earn their } \\
\text { graduate degree in engineering. } \\
\text { Returners indicate interest in advanced engineering topics as a reason to } \\
\text { Interest value } \\
\text { Rtturn to earn a graduate degree. } \\
\text { Returners indicate that having a graduate degree in engineering is } \\
\text { fundamentally aligned with how they see themselves. } \\
\text { Returners indicate advantages to having a graduate degree in engineering } \\
\text { that will further them in their career goals. } \\
\text { Rost }\end{array} \quad \begin{array}{l}\text { Returners indicate sacrifices involved in making the decision to return to } \\
\text { earn an engineering graduate degree. }\end{array}$ \\
\hline
\end{tabular}

proportion of discussion about each type of value was ranked, with 1 representing the most discussion and 3 representing the least. The difference between ranks ( 1 and 2, 2 and 3 ) is not equivalent; in some cases, the relative importance of two value types was very close, while in other cases there was a greater difference in importance. Value types with the same rank across multiple participants indicate order of rank; but rank order does not mean that the participants placed the same weight on that value type.

In the same way as we determined relative weight of interest, attainment, and utility values, we analyzed the cost categories for relative importance for each of our participants and ranked the relative importance of each cost category, with 1 representing the highest ranked cost, and 4 representing the lowest ranked cost. We did not do this analysis for cost-reduction strategies because the two are related; that is, the significance of a cost to participants was also reflected in the ways they discussed reducing costs of returning.

Two coders analyzed the data for instances of the deductive codes and the development and coding of the instances of the inductive themes. We used a consensus coding approach; the coders worked collaboratively, reading and coding separately for a segment of the data, then discussing findings. All sets of data were iteratively coded until consensus was reached (Patton, 2002).

\section{Findings}

While our study participants were a diverse group (including both master's and doctoral students, covering a wide variety of ages, and including two participants with significantly larger gap years), in our data analysis, we did not find any significant differences due to this diversity. We did discover some preliminary trends based on level of importance, which we discuss at the end of the section. Thus, we report our findings for the participants as a group, and not as particular to any of these potential subvariables. In the following, guided by EVT we discuss findings related to expectancy and the non-cost related values of attainment, interest, and utility. We continued to use the EVT framework in our analysis of costs, but also subdivided the cost category. We discuss each of the cost subcategories as well as the costreduction subcategories.

\section{Expectancy}

Our study participants did not have serious doubts about their abilities and expected that they would be able to earn the graduate degree they were pursuing. Their comments about their ability to succeed, while brief, were emphatic. Brenda put it very succinctly: "I had to 
believe in myself when no one else did." When talking about her plans to return, she stated, "I completely had the whole system worked out for success." While the returners in our study did occasionally feel discouraged, they typically expressed it as a mildly difficult episode. Any thoughts participants had of dropping out were based not on whether they thought they would fail but on whether achieving a graduate degree was worth the effort. Our participants did not express expectation of success as an important determining factor in their decision to return and to complete their degrees.

\section{Motivating Values for Returners}

In this section, we focus on our second research question: What values motivate practitioners to go to graduate school? We discuss evidence of attainment, interest, and utility value in participants' decisions to return, summarize trends across the data set, and provide sample excerpts to demonstrate what this pattern looked like in the context of participants' experiences. Finally, we compare the weight of each of these types of values in the decision for participants to return to graduate school.

Attainment value Participants did not strongly identify their pursuit of a graduate degree with their sense of self. However, as one example, Catherine's comments showed some attainment value, since she felt that an important aspect of her self-identity involved making a difference in the world, and a graduate degree was a key part of that:

I'm doing this because it matters. . . . My goal is to grow as a human being, to become more knowledgeable, and to bring that knowledge back . . . to the aerospace community overall, and to improve the planet earth.

While Catherine slightly touched on attainment value as a factor in her decision to return, in most interviews, no statements could be coded as attainment value.

Interest value Some participants indicated that their pursuit of a graduate degree was influenced by their personal interest in the field or a particular research area. Catherine expressed this in terms of expanding her horizons, as distinct from the professional benefits that she could realize from the degree.

My motivation was more to learn something new, to expand my horizons, and to grow personally - and if that opened doors professionally, that was icing on the cake. ... And let me say, I'm excited about ... the doors it might open as well. But that was not my main, my motivation for being here.

In Ian's situation, two decision makers were involved in his returning. Since he is activeduty military, the decision was subject to veto by the military. His decision thus was affected by both his personal motivation and the military's judgment of the degree's value. His personal motivation displayed elements of interest value. As he explained it:

I want to learn as much as I can. And, like I said at the beginning, that's kind of the motivator - it's for the Army, it's to teach, so I can become a better professor. But part of me was like sitting in the army going, I realize that I'm losing a lot of the stuff that I went to undergrad for . . . I don't want it to be for nothing. Even if just for my personal benefit, even if it's not for employment.

Utility value All participants expressed great evidence of utility value. The utility seen by the participants differed, however, since they had different life circumstances and career 
objectives. For several participants, the utility was the desire to expand their skills, and thus the opportunities open to them in their current line of work, or shift their work emphases. For example, Andrew was working in industry when he decided to return to school, and he planned to shift his research area when he returned to industry.

Now, at the time I decided to come back, part of the reason was that I was in R\&D, and it had been pointed out to me that getting a $\mathrm{PhD}$ would be more useful as far as mobility within an R\&D environment, as well as the particular company I was working for . . . . To make . . . a sideways move in R\&D can be difficult if you don't have experience in a given area. . . I I had an idea of the kind of research I wanted to do, and so I figured if I could go back to school and do that research, that would be a way to get into that area.

Danielle also held a research position; but her utility in pursuing a doctoral degree was the ability to control her own funding and define her own research direction.

Now, what I find is that unless I have a $\mathrm{PhD}$, you cannot own your own funding, no matter how many papers you've written. . . So you have to have a $\mathrm{PhD}$, and you can't even be a post-doc. Post-docs still cannot own their own funding, under a P.I.'s name. So you have to attach a P.I. and trust that he or she will not take that money from you. All right, when I was with my previous employer, I was able to do that with a master's. I could have my own funding, under my name. So you get to sign off on expenses, sign off on people's time. You can decide who you're going to hire for your research projects ... Run the project the way you want it . . Define the directions that I want.

Other participants wanted to change from an industrial career to a teaching career. Evan stated that he had always considered coming back at some point, though the timing was uncertain, when he had graduated with his undergraduate engineering degree.

I was interested in eventually getting my $\mathrm{PhD}$ and teaching, and that . . . [was] my goals going in. . . . The short term, I guess, was I was tired of working, and I felt like I wasn't learning anything new. So my first goal, I guess, was to really begin to learn more and feel like I was really using my brain again. But my ultimate goal is to stay in academia and teach.

Similarly, John expressed a strong desire to teach at a university and also stated that he had always intended to pursue further education, although he had been out of school longer than he had originally planned.

It's something that I've always wanted. I always figured I was going to go work for a few years and return, at least to get a master's degree. That was my first goal. But ultimately, after working for several years, I had decided that I didn't really want to work in industry. I wanted to have more freedom to do research, to investigate stuff, and so I came back. And I love to teach. So that's why I came back. To become a university professor is my goal.

Returners saw significant utility value in obtaining their graduate degrees. This value was more important to our returners than either attainment value or interest value, and was the primary driver in their decision to pursue graduate education. The results show several types 
of utility value were realized: transitioning into an academic career, advancing further in the same area in a current career path, or changing research field or specialty within a current career path. A full discussion of the utility values seen by our participants is included in our previous work (Peters \& Daly, 2012).

\section{Comparison of Value Types}

The analysis of attainment, interest, and utility values revealed that utility value was the primary motivation to earn a graduate degree. This trend is represented in Table 4, where 1 is the highest ranked value and 3 is the lowest ranked value, based on emphases participants placed and the presence (or absence) of each of these values in our participants' explanations of their motivation to return. For all participants, utility value was ranked either first or second, with nine of the 10 participants showing utility value as the highest ranked value. Interest was next in importance, rated as first by one person and second by nine. Attainment value was not mentioned in most interviews. Since the open-ended nature of the questions allowed attainment to be brought up, and attainment was mentioned by Catherine, we concluded that our participants did not place much emphasis on this value. Therefore, attainment was the lowest ranked value. No significant patterns emerged according to gender or age.

\section{Costs for Returners}

Types of returning costs were classified into intellectual, balance, cultural and environmental, and financial costs on the basis of emergent patterns in the data (see Table 5). The following section discusses these cost types and answers our third research question about the costs encountered in the returning experience.

While the significance of various costs differed from one participant to the next, all participants were concerned with the costs they faced in returning and completing their graduate education, and they weighted those costs against the value of a graduate degree in order to decide whether to return and stay.

Intellectual costs Intellectual costs are the struggles and sacrifices experienced due to issues such as forgotten material, computer skills, study groups, and curriculum. Those who had fewer gap years typically spoke more about having to relearn material they had forgotten. Evan was one example of this.

Table 4 Weight Given to Types Values Associated with the Returning Experience

\begin{tabular}{lccc}
\hline & Attainment & Interest & Utility \\
\hline Andrew & 3 & 2 & 1 \\
Brenda & 3 & 2 & 1 \\
Catherine & 3 & 1 & 2 \\
Danielle & 3 & 2 & 1 \\
Evan & 3 & 2 & 1 \\
Felicia & 3 & 2 & 1 \\
Gary & 3 & 2 & 1 \\
Harald & 3 & 2 & 1 \\
Ian & 3 & 2 & 1 \\
John & 3 & 2 & 1 \\
\hline
\end{tabular}


I spent a lot of time . . . I worked really hard late at night . . . and did a lot of extra problems out of the backs of the books to really make sure I understood the stuff. My first semester was really tough. . . . I had hard classes, I think . . . It was a math class, and I hadn't taken a real math class in years. And then the other class was a really theoretical class. . . . They were tough classes for me. . . . Second semester was better, and while I still did a lot of extra problems out of the books, to make sure I understood what was going on in classes, I made more time for research, and I think the classes ... were coming easier, even second semester, than they were the first semester.

Many participants also felt that their software skills were insufficient. In particular, several cited having to relearn Matlab, which is used in many engineering classes. Andrew, in particular, was surprised and frustrated at having to spend time relearning Matlab.

I used Matlab extensively, and then I didn't use it. And then going back, I mean it changed a little, it didn't change that much, but still trying to relearn all that . . . took a surprisingly long time, even though I used it extensively in the past. So, that was a surprise. ... It felt frustrating because you knew you knew it at one time.

These intellectual costs affected more than just the participant's own coursework; in one case, they affected his job performance. Harald was funded as a graduate student instructor and found that he had forgotten much of the material that he needed to teach.

It was about 10 years between teaching - between having that class and teaching it - so a lot of those things in the lower level general classes, you don't really use in the upper level classes. . . They kind of get pushed to the back. . . . So basically I had to ... relearn the class before I could teach it. And that was pretty difficult, that was time consuming. Very time consuming.

Since the returners recognized that working with others helped them learn and that finding study partners or groups was important, they indicated that a lack of study partners or groups was sometimes a cost that could put them at a disadvantage in courses. Returners had to be active in seeking out groups to work and to study with. In Danielle's case, younger students usually had not asked her to join study groups as they formed them; therefore, it had been important for her to take the initiative. She reports her approach:

Now, I'm not shy about asking people, "Can I study with you? Can I study with you? Can I meet with you?"

Study partners or groups is an important component of graduate study, since working in teams is a key way to complete projects, and is sometimes a requirement for the assignment. Difficulties in finding effective groups added to the returners' intellectual challenges.

Balance costs Participants indicated they struggled to balance graduate study with significant commitments outside of school, such as with their family, community, and personal health. Six of our participants specifically mentioned a spouse or children as affecting their decision to return. Even those who did not mention family obligations expressed concern about how their studies would affect their relationships and activities. Ian explained the challenge he had balancing his responsibilities and the graduate school experience.

And there's other distractions that I have now. I have a wife, she's pregnant; I have a $\operatorname{dog} . .$. and I've got a house that I bought and I'm trying to maintain. So there's other 
Table 5 Cost Categories

\begin{tabular}{|c|c|c|}
\hline Cost & Description & Components \\
\hline Intellectual & $\begin{array}{l}\text { Struggles and sacrifices related } \\
\text { to learning content in graduate } \\
\text { engineering programs }\end{array}$ & $\begin{array}{l}\text { Needing to relearn material for } \\
\text { some classes } \\
\text { Difficulties working alone; lack of } \\
\text { social construction of knowledge } \\
\text { Spending time on topics already known } \\
\text { from work experience } \\
\text { Material returners never had, but the } \\
\text { younger students did }\end{array}$ \\
\hline $\begin{array}{l}\text { Cultural \& } \\
\text { environmental }\end{array}$ & $\begin{array}{l}\text { Struggles and sacrifices related to } \\
\text { being in a different environment } \\
\text { and having different colleagues }\end{array}$ & $\begin{array}{l}\text { Learning a new environment or } \\
\text { university culture } \\
\text { Finding teammates; team interactions } \\
\text { Getting "demoted" } \\
\text { Time away from the work world }\end{array}$ \\
\hline Balance & $\begin{array}{l}\text { Struggles and sacrifices related to } \\
\text { proportioning time for graduate } \\
\text { engineering work with outside } \\
\text { social and personal responsibilities }\end{array}$ & $\begin{array}{l}\text { Less time for community involvement } \\
\text { Less time for family interactions, } \\
\text { (children, spouse) } \\
\text { Less time for hobbies and personal interests }\end{array}$ \\
\hline Financial & $\begin{array}{l}\text { Struggles and sacrifices related to } \\
\text { money }\end{array}$ & $\begin{array}{l}\text { Cost to pay tuition } \\
\text { Cost in salary cuts } \\
\text { Cost for insurance } \\
\text { Change in financial confidence }\end{array}$ \\
\hline
\end{tabular}

distractions. . . . I envy some of the kids here that . . . just went straight from undergrad to grad. ... They really don't have anything else to do, so they're hanging out . . . and studying. . . . I wish I could do that, but I've got to go home and see my wife, and I've got to go ... take the dog out.

Catherine brought up issues surrounding both family and community, and contrasted these issues with the typical graduate student and the way that graduate school is structured.

I have to figure out how to help my parents out, and where they're going to retire, and how I can be supportive to them. I basically emotionally adopted my niece; I am working in my church; I do volunteer work in the community; I'm in the PTSA at my son's school. So my life is very much outside. There's other things I'm involved in; my life is much more integrated with the community. . . Well, the entire system of graduate study makes a reasonable assumption, and that is that you're in your twenties, and you're single, and you have no children, and you have no life outside of graduate school. . . . The workload is designed for you to be able to work $24 / 7$, roughly speaking. That is so not my case. It's not even funny. I can't work 24/7.

Cultural and environmental costs Cultural and environmental costs included feelings about changing from the work environment to the university environment, adjusting to different expectations and norms, and experiencing a feeling of "demotion." These costs were significant to those who had experienced success for a period of years as a professional in the workforce. For example, John faced substantial challenges in adjusting to the culture of graduate school; in his case, the work patterns and norms were the most significant issue. 
I'm used to working at my job all day long and going home and being done with it at the end of the day. ... . So that's one transition that was tough, and I'm still not even there. I really don't do work at home. I do some, but . . . I don't have that ability anymore. It's - I leave it at work, and I just don't really. . . complete it afterwards. Switching tasks. I mean, grad school's . . . all about switching tasks, lots of little tasks, manage your time, about multiple little projects. Work is more consistent, like you know what you're doing today, you're finishing this project . . . there are some breaks, but really you have your project, and you're finishing, you're working on one goal, and you don't really need to continually be changing, shifting gears . . . And so that has been tough . . . I've gotten it back, but that was something that did definitely atrophy, that I didn't have to do so much when I was working.

There was also a cultural aspect to returners' difficulties in finding study groups and working with them effectively, in addition to the intellectual aspects discussed previously. Their attitudes, outlooks, and priorities sometimes differed from direct-pathway students, and they sometimes felt disconnected from fellow students. Andrew, for example, found that he grew frustrated working with other students on projects.

They don't really know how to interact with people, they don't know how to work in groups in a way that is sort of equitable to everybody, they're all very self-absorbed, self-focused, really focused on getting work done no matter the quality, and trying to push work off onto other people, and not really doing a lot of listening, these types of things. And so I found that very frustrating.

These cultural and environmental costs were, to some extent, anticipated by the participants, and accepted as part of the price to pay for returning to school.

Financial costs In addition to tuition cost, if applicable, participants cited as financial costs the loss of income while they were out of the workforce, the need to ensure that they had benefits such as medical insurance, and the difficulties finding adequate funding. For example, Andrew expressed concern for the ability to find fellowships.

But maybe the most awkward thing was . . you're hopping onto a new project that you're not continuing from a master's or anything like that and so suddenly you're trying to jump right in and apply for fellowships of something that's . . . that you're just proposing that hasn't been done, you have no results, and so . . . I feel like there's a big challenge there to get a fellowship because there's no results . . . no work to refer to.

Similarly, Gary felt at a disadvantage in writing fellowship proposals. As a returning master's student with an interest in a $\mathrm{PhD}$, he considered applying for fellowships, but ultimately decided against it.

I hadn't applied for any fellowships or anything, because . . . I mean, honestly, I've been out of school a long time, I didn't have a good enough direction to write a fellowship proposal, I felt . . . the academic world's a closed environment, is what I think. I think you're sitting with professors, and they tell you what good ideas are and bad ideas are when you write a proposal to a fellowship committee . . you have your finger on the pulse of what's hot in academia . . So I do think that it's a little harder to write proposals to get funding. 
Financial costs were a concern to all of the participants, but many of the master's students faced the additional challenge that, at a major research university, most funding was allocated to doctoral students.

Comparison of costs The costs faced by each participant were ranked from 1 to 4 , in the same way as the values of returning, with 1 representing the most highly ranked costs and 4 the least highly ranked. Cost emphases for each participant are shown in Table 6, including average values across participants.

All of the costs were important to our participants, although different participants emphasized different costs over others. The intellectual costs of graduate school greatly affected most of the participants in our study, including those with a smaller work gap before returning, and they indicated these were significant costs of the returning experience. The importance of balance costs was strongly correlated with family status, with those who were, or were about to become, parents displaying a higher rank for these costs. Even among those who were childless or single, however, balance costs still affected their graduate school experiences. The lack of clear trends in the significance of the costs demonstrates that the experience of returning to school is complex, and multiple issues are involved in returners' decisions.

\section{Cost Reduction and Mitigation}

All participants had developed strategies that allowed them to reduce or mitigate the costs they faced in the pursuit of a graduate degree. We represent these as cost reducers. These category titles parallel the cost categories, and are shown in Table 7. The following discussion addresses our fourth research question on the factors that mitigate costs for returners.

Intellectual cost reducers While many participants spent significant amounts of time relearning material, they tried to do so as efficiently as possible. One key concern was what material needed to be relearned, and what resources were best for doing so. Making these choices was a major issue for Ian, who found that certain books were particularly useful to him.

I bought Calculus for Dummies and I bought Calculus 2 for Dummies, and they were really helpful. . . . I had to go buy a book called Introduction to Matlab for Engineers and Scientists. It's for guys who've been out, and start off with like here's how you do basic math on Matlab, and work all the way through programming.

Several participants explained their situation to the professors who taught the course they were taking and sought advice from them. Andrew said,

If you go to a professor and say, "I'm not understanding this" . . . that was the other thing I learned is . . . I used to not go to professors . . . I'd always just try and figure things out myself, and then afterwards, I'm like, well, that's silly. I should just go to them, and you know they can probably save me like an hour or two of . . . wasting my time.

In other cases, rather than going to professors, returners went to fellow students for help. For example, Felicia found that her classmates were an extremely useful resource.

I was able to meet some nice people in my classes who . . . had gone straight to grad school or they had a smaller gap in between, and so the stuff was a little more fresh. So I at least had people, like in addition to my professors, like if there was a question that I thought was kind of embarrassing to ask, I could ask them and not feel so dumb about it. 
Table 6 Importance of Types of Costs

\begin{tabular}{lcccc}
\hline & Intellectual & $\begin{array}{c}\text { Cultural and } \\
\text { environmental }\end{array}$ & Balance & Financial \\
\hline Andrew & 1 & 3 & 4 & 2 \\
Brenda & 4 & 2 & 1 & 3 \\
Catherine & 1 & 2 & 3 & 4 \\
Danielle & 3 & 2 & 1 & 4 \\
Evan & 1 & 4 & 3 & 2 \\
Felicia & 2 & 1 & 3 & 4 \\
Gary & 3 & 4 & 2 & 1 \\
Harald & 1 & 2 & 3 & 4 \\
Ian & 1 & 1 & 2 & 4 \\
John & 3 & 2.3 & 2.5 & 3.2 \\
Average rank & 2.0 & & & \\
\hline
\end{tabular}

While the importance of intellectual costs was not correlated with the length of returners' gap between undergraduate and graduate school, the cost reducers used by returners varied according to the length of the gap. Those with relatively short gaps were much more willing to relearn the material. Those with a longer gap used other strategies; they were typically aware of the professors whose courses were best suited to their own situation, and chose classes to suit their own strengths, weaknesses, and future plans.

Balance cost reducers Since maintaining a good balance between academic life and personal life was important to many participants, they developed a variety of methods to do so. Several participants took fewer classes than did other students. They could then keep up with the nonacademic demands on their time and also learn the material better.

Several participants reduced costs by allocating their time at home carefully. Danielle, in particular, spoke of this.

I have a housekeeper . . . I really got good sitters . . But the thing is, it doesn't replace my time at home ... So I do have my sitters judiciously placed, certain time, that is, that doesn't take that quantity and quality time away from the kids. But things like household stuff - the trick is to not burden your spouse too much.

Several participants mentioned good time management, and not wasting time when they were at school or in the lab. As Evan said,

When I'm in the lab ... I want to be working on my stuff, and I don't want to be screwing around so that I have to come in and work more hours.

Similarly, other participants found balance by being very focused and working hard when on campus, and spent their noncampus time with family and friends.

Cultural and environmental cost mitigation Participants found several means to reduce and mitigate the effects of cultural and environmental costs, including finding a support system, role models, and mentors. One of the most significant ways participants mitigated cultural and environmental costs was by finding common ground with younger students. While they perceived definite differences between themselves and direct-pathway students in their circumstances and life experiences, all participants found ways to connect with those students. Andrew saw himself as being, in a sense, "on the same side" as the other students. 
Table 7 Cost Reduction and Mitigation Categories

\begin{tabular}{|c|c|}
\hline Category & Reduction and mitigation strategies \\
\hline Intellectual cost & $\begin{array}{l}\text { Finding a support system (study groups, campus organizations) } \\
\text { Finding good resources for re-learning material } \\
\quad \text { (particular books, auditing classes) } \\
\text { Planning class schedules wisely } \\
\text { Choosing a program well suited to current knowledge and needs }\end{array}$ \\
\hline Cultural \& environmental cost & $\begin{array}{l}\text { Finding a support system } \\
\text { Establishing common ground with other students } \\
\text { Choosing fitting study partners } \\
\text { Having good mentors } \\
\text { Finding role models in similar situations }\end{array}$ \\
\hline Balance cost & $\begin{array}{l}\text { Maintaining involvement outside of school } \\
\text { Preparing family for the experience } \\
\text { Receiving tailored information about the university and } \\
\text { surrounding community }\end{array}$ \\
\hline Financial cost & $\begin{array}{l}\text { Finding fellowships and scholarships } \\
\text { Employer support for degree } \\
\text { Reductions in expenses } \\
\text { In-state tuition }\end{array}$ \\
\hline
\end{tabular}

[We're] generally all learning something new in a given class, or something like that. We ... have the same deliverables we have to deal with, we have the same stresses about getting a project done, or learning how to use a new software, or whatever ... You're all on the same side.

In contrast to Andrew's focus on common experiences, Brenda focused on common interests.

I think in general the commonality is the overall enthusiasm for doing things that most of the world thinks is boring. That's a good commonality. ... When you go into this area, you really - most people go into it because they're interested in it. . . If you can focus discussions around the spark of inspiration, then you can find a lot in common with young people.

These common experiences and interests helped returners to feel integrated into the community and to find a way that they could become part of the university's culture.

Financial cost reducers Each participant had to to pay for graduate school and handle the loss of income while pursuing a graduate degree. Since Catherine and Ian worked for employers who paid for their graduate studies, they needed to work within their employers' requirements. For Catherine, there was a time requirement: she had to complete her coursework within two years, then return to work while she finished conducting her research and writing her dissertation. For Ian, there was an additional service obligation; for each year that he spent in graduate school, he owed the Army an additional two years of service.

Several participants sought out fellowships and graduate assistantships for research or teaching. While this was a straightforward process for some returners whose advisors had funding for projects that interested them, others took the initiative to find funding for the work they wanted to do. Danielle, in particular, actively sought funding for the work she wanted to do. 
I scanned on "women" and "engineering" and came out with a handful of scholarships. . . . So I applied to the [Name] fund - fellowship . . . That's a three-year . . . tuition-paid stipend . . . but that fellowship only gives you $\$ 4500$ in tuition. So the leftovers I got from [University Graduate School Office], actually because I won a [University Graduate School Office] non-traditional fellowship. That one, the department simply told me ... [you are] one of the few candidates that qualify for this fellowship, should we nominate you? And I'm like, yes, please. . . . Yes, of course nominate me for this. I also applied to [another fellowship]. . . . And so I combined them all, and I just stacked them up.

Those who were pursuing master's degrees, such as Felicia and Gary, were less likely to find funding to pay for school, and had to cover their own tuition. In these cases, they minimized the impact by choosing a school where they could pay in-state tuition, lowering their required cost.

\section{Discussion}

Returners' decisions to return and complete an engineering graduate program can be understood as a function of their expected value of graduate education and the costs associated with getting that education. As one participant stated,

Three to five years or more of a lot of pain. Is the pain worth the gain? Is it worth that pain, even on your personal life, your family? It's a nontrivial decision.

This concern with the amount of "pain" involved in the returner's life can be understood in terms of types of cost, while the gain can be understood in terms of the other elements of value. Expectancy value theory is an effective means of understanding this balance.

\section{Comparison of Findings with Existing Work}

Expectancy plays a significant role in undergraduate students' decisions to complete or leave engineering majors (Matusovich et al., 2010). In our work, though, expectancy of success was not a key factor in participants' decisions to return. The balance between cost and other values was the key factor in our participants' decision to pursue graduate degrees. If we had included in our sample those who had considered returning but decided against it, expectancy would likely play a larger role in the decision to return. In our cases, participants already expected they could succeed prior to deciding to return, and the experience of graduate school did not cause them to question this expectancy. The question was not whether they could successfully complete a graduate degree program but whether it was worth doing.

In deciding whether the value of a graduate degree outweighed the costs, attainment value played the least important role. This is a significant contrast to the results found by Matusovich et al. (2010) in a study of undergraduate students, in which attainment value was highly significant for half of the study participants. Participants in our study had already completed technical degrees and established professional identities; receiving an additional degree did not seem to have significantly affected their identities as professionals in their disciplines. Interest value, while it was more significant than attainment value, did not serve as a motivator to return by itself. Because our participants were professionals, they had a variety of ways to pursue their technical interests, and interest alone would not justify the sacrifices that they foresaw in planning their return. The primary value they saw in a graduate degree was utility. Participants had a direct application for the degree, both for the credential itself 
and for the knowledge gained in their studies, and needed the degree to accomplish these goals. This finding also contrasts with those of Matusovich et al., which showed significantly less emphasis on utility for engineering undergraduates. Thus, in our study, values driving returners to earn their graduate degrees differed from those driving undergraduates to earn engineering degrees. Further studies are necessary to conclude if this is the case for the larger returning student graduate population. Additionally, how our study participants compare to the larger population of graduate students is an open question.

Participants faced many costs in their return to graduate school. Intellectual costs greatly affected most of our returners, and these costs were more significant to them than to directpathway students. While returners had gained many important skills and had used some of what they learned as undergraduates in their professional careers, they had to relearn other material as it was needed. Instead of relearning the material, some participants found a degree program that gave them flexibility in curriculum requirements. They felt frustrated with study groups and collaborating with direct-pathway students because they had to spend time on topics that they already knew from their work experience or had to learn new material that was not included in their undergraduate coursework. This finding is consistent with Prusak's (1999) study of adult learners and the challenges they faced "catching up" with direct-pathway students.

"Fitting in" to the traditional graduate student culture is an obstacle often reported in other work on returning students (Gardner, 2008; Schilling, 2008; Strutz et al., 2011). The returners in our study also struggled to fit into the community culture. More specifically, returners felt "demoted" by ways graduate education is structured; this feeling can be exacerbated if faculty do not recognize and respect the experience returners have, and show they want to help returners connect their professional knowledge to their graduate work. The feeling of difference from direct-pathway students was also evident in the cost category of balance. Many returners saw that their non-school responsibilities differed from those of their direct-pathway peers, and felt their graduate student colleagues did not always understand or accommodate these responsibilities. The struggle to fit in was also seen in returners' intellectual interactions with their colleagues when they often found themselves teaching their fellow students and teammates. While peer teaching is of value to the graduate student community as a whole, our returners were frustrated at the loss of time spent doing this when they were trying to allocate their time appropriately, unless it benefited their own success.

\section{Limitations and Future Work}

Our study has several limitations. One is that the study sample is from one research university. Differences may appear at a different type of institution and across multiple institutions, but we cannot predict what those differences may be. While our sample size was adequate to address our specific research questions, it was not large enough to determine whether there are significant differences within the population of returners. The study is also limited by the interview protocol used. We structured the interview with open-ended questions in order to allow participants to raise any beliefs, obstacles, and successes associated with returning; however, this method precluded the possibility of probing specifically for different types of value or costs. Finally, since we studied only returners, it is not possible to perform a direct comparison between returners and direct-pathway students.

In a review article about EVT, Wigfield and Cambria (2010) indicated that cost values are the least studied in the framework. Our study thus contributes to how we think about 
and operationalize cost values within adult groups, particularly with regard to engineering practitioners returning to school. Our findings can be a basis for future work on costs and cost reducers in adult education experiences. Our future work will focus on gaining deeper insight about the returning experience of engineering students by expanding the population to investigate subpopulations within the returner group, comparing the returning experience across multiple institutions, and comparing the returning experience to the direct-pathway experience. We also plan to collect data to inform evidence-based program development to support returners and to guide evaluation and improvement of existing programs.

\section{Recommendations}

\section{Recruitment}

The experiences of returners shape the reputation of the returning experience for potential returners. An experience with high costs and little support will influence the ways returners advise other potential returners. Potential returners may not do so on the basis of the experience and advice of their professional peers who have returned. Thus, recruiting potential returners means supporting present returners.

Because the impact of costs will vary according to the returner, supporting returners requires changing many components of the returner's experience. Walker, Golde, Jones, Bueschel, and Hutchings (2008) described ways to reconsider graduate programming by redefining goals and then aligning assessments and education experiences to meet these goals. This approach applies to the recommendations arising from our work. In some cases, returners can achieve the same goals of graduate school as do direct-pathway students, but in a new ways. To support the success of returners, changes in graduate education must be made in three areas: admissions, degree requirements, and community awareness.

\section{Admissions}

Admissions decisions should be based on a holistic view of prospective students, and the factors considered should be weighted toward the data that gives the most meaningful information about an applicant's current capabilities; this policy should be clear in application materials. For example, letters of recommendation are often expected to come from faculty at a student's previous institution. But in the case of returners, such letters may be difficult to obtain due to the retirement or death of faculty members who knew them. Nor may such letters be useful in the graduate admissions process because they present an outdated picture of a candidate's abilities. Universities should allow alternative letters of recommendation so that candidates can represent their current capabilities. The GRE and undergraduate grades may not accurately indicate a returner's potential (Purdy \& Washburn, 2005). Because returners have often proven through their previous work experience that they have the necessary mathematical, verbal, and writing skills to succeed in graduate school, they should be able to provide supplemental materials in addition to previous grades and GRE scores; universities should consider these materials alongside GPA and test scores instead of abiding by a minimum score for acceptance.

\section{Degree Requirements}

Returners could benefit from greater flexibility in course scheduling, enrollment policies, and timelines. For example, a student without the prerequisite for an advanced engineering course but with years of experience applying the subject matter of the prerequisite should be 
able to have this course waived. Departmental procedures should allow for expected or required courses to be waived or replaced with other courses, when situations warrant, and should have a standard appeal or petition process for students to request this accommodation. Such processes should be published on university Web sites and in course catalogs. Qualifying and readiness exams should reflect the actual graduate experiences of individual students, rather than the typical courses taken by most students. Many graduate programs require continuous enrollment and have a time limit for degree completion. Returners likely have greater family responsibilities than direct-pathway students, and enrollment requirements, timelines, and residency policies should be flexible enough to accommodate such returners.

\section{Supportive Academic Community}

Helping returners succeed will require disseminating information about the support available within the university and about the experiences and strategies of successful returners to potential returners. Universities should account for the differences between returners and direct-pathway students. They should develop programs such as faculty awareness initiatives because faculty advisors have a significant impact on the graduate student experience (Lovitts, 2001). University efforts could include teaching faculty instructors to better integrate returners into student teams, development of tutoring services to meet the specific needs of returners, and offering preclass software catch-up programs to familiarize returners with software currently used in the curricula.

Programs can provide information about the experiences of successful returners and the strategies they used to succeed. Universities could inform their own students about success strategies through a Web site or returning student group and should also inform potential returners about the costs they will face, so they can formulate plans to deal with these costs.

\section{Conclusions}

While returners can add their perspectives to the classroom environment and pursue research directions that direct-pathway students do not, they face significant costs and impediments in their pursuit of a graduate degree. These costs and the noncost values of the degree that successfully motivate some returners to complete their graduate education, are not well understood. This study described the values that prompt returners to pursue a graduate degree, investigated returners' expectations of success, and identified both the costs they face and their strategies for reducing and mitigating them. Using this information, potential returners can more effectively plan for success in the graduate environment, and universities can develop initiatives to better attract returners and support their success.

\section{Acknowledgements}

We thank Steven Skerlos for his assistance with participant recruitment and understanding local graduate student contexts, and Nancy Love for her advice about graduate student academic policies.

\section{References}

Baker, S., Tancred, P., \& Whitesides, S. (2002). Gender and graduate school: Engineering students confront life after the B. Eng. Journal of Engineering Education, 91(1), 41-47. 
Bassett-Jones, N. (2005). The paradox of diversity management, creativity and innovation. Creativity and Innovation Management, 14, 169-175.

Battle, A., \& Wigfield, A. (2003). College women's value orientations toward family, career, and graduate school. Journal of Vocational Behavior, 62, 56-75.

Boe, M. V., Henriksen, E. K., Lyons, T., \& Schreiner, C. (2011). Participation in science and technology: Young people's achievement-related choices in late modern societies. Studies in Science and Education, 47(1), 37-72.

Ceci, S., \& Williams, W. (2007). Why aren't more women in science? Top researchers debate the evidence. Washington, DC: APA.

Chubin, D., May, G., \& Babco, E. (2005). Diversifying the engineering workforce. Journal of Engineering Education, 94(1), 73-86.

Conrad, C., Haworth, J., \& Millar, A. (1993). A silent success: Master's education in the United States. Baltimore, MD: Johns Hopkins University Press.

Eccles, J. S. (2005). Subjective task value and the Eccles et al. model of achievement-related choices. In A. J. Elliot and C. S. Dweck (Eds.), Handbook of competence and motivation (pp. 105-121). New York, NY: Guilford Press.

Eccles, J. S. (2009). Who am I and what am I going to do with my life? Personal and collective identities as motivators of action. Educational Psychologist, 44(2), 78-89.

Eccles, J. S., Barber, B. L., Updegraff, K., \& O’Brien, K. M. (1998). An expectancy-value model of achievement choices: The role of ability self-concepts, perceived task utility and interest in predicting activity choice and course enrollment. In L. Hoffmann, A. Krapp, K. A. Renninger, \& J. Baumert (Eds.), Interest and learning: Proceedings of the Seeon Conference on Interest and Gender (pp. 267-279). Institute for Science Education at the University of Kiel: IPN.

Feagin, J. R. (1984). Racial and ethnic relations. Upper Saddle River, NJ: Prentice-Hall.

Fereday, J., \& Muir-Cochrane, E. (2006). Demonstrating rigor using thematic analysis: A hybrid approach of inductive and deductive coding and theme development. International Journal of Qualitative Methods, 5(1), 80-92.

Finke, R. A., Ward, T. B., \& Smith, S. M. (1992). Creative cognition: Theory, research, and applications. Cambridge, MA: MIT Press.

Fishbein, M., \& Ajzen, I. (1972). Attitudes and opinions. Annual Review of Psychology, 23, 487-544.

Fredricks, J. A., \& Eccles, J. S. (2002). Children's competence and value beliefs from childhood through adolescence: Growth trajectories in two male-sex-typed domains. Developmental Psychology, 38(4), 519-533.

Frome, P. M., Alfeld, C. J., Eccles, J. S., \& Barber, B. L. (2006). Why don't they want a male-dominated job? An investigation of young women who changed their occupational aspirations. Educational Research and Evaluation, 12(4), 359-372.

Gardner, S. K. (2008). Fitting the mold of graduate school: A qualitative study of socialization in doctoral education. Innovations in Higher Education, 33, 125-138.

Hennessey, B. A., and Amabile, T. M. (1998). Reward, intrinsic motivation, and creativity. American Psychologist, 53(6), 674-676.

Hofinger, R. J., \& Feldmann, L. J. (2001). The role of the adult student in the classroom. Proceedings of the American Society for Engineering Education Annual Conference E Exposition, Albuquerque, NM.

Howard-Hamilton, M., Morelon-Quainoo, C., Johson, S., Winkle-Wagner, R., \& Santiague, L. (Eds.). (2009). Standing on the outside looking in: Underrepresented students' experiences in advanced degree programs. Sterling, VA: Stylus. 
Iles, P., \& Hayers, P. K. (1997). Managing diversity in transnational project teams. Journal of Management Psychology, 12(2), 95-117.

Knowles, M. (1980). The modern practice of adult education: From pedagogy to andragogy. Wilton, CT: Association Press.

Latimer, R. L. (1998). The case for diversity in global business, and the impact of diversity on team performance. Competitiveness Review, 8(2), 3-17.

Lindlof, T. R., \& Taylor, B. C. (2002) Qualitative communication research methods (2nd ed.). Thousand Oaks, CA: Sage.

MacFagden, L. (2008). Mature students in the persistence puzzle: An exploration of the factors that contribute to mature: students' health, learning, and retention in post-secondary education. Montreal, Quebec: Canadian Council on Learning.

Matusovich, H., Streveler, R., \& Miller, R. (2010). Why do students choose engineering? A qualitative, longitudinal investigation of students' motivational values. Journal of Engineering Education, 99(4), 289-303.

Matusovich, H., Streveler, R., Loshbaugh, H., Miller, R., \& Olds, B. (2008). Will I succeed in engineering? Using expectancy-value theory in a longitudinal investigation of students' beliefs. Proceedings of the American Society for Engineering Education Annual Conference Eo Exposition, Pittsburgh, PA.

Nagy, G., Trautwein, U., Baumert, J., Koller, O., \& Garrett, J. (2006). Gender and course selection in upper secondary education: Effects of academic self-concept and intrinsic value. Educational Research and Evaluation, 12(4), 323-345.

National Science Foundation (NSF). (2012). Research in engineering education solicitation. Retrieved from: http://www.nsf.gov/funding/pgm_summ.jsp?pims_id=503584.

Nettles, M., \& Millett, C. (2006). Three magic letters: Getting to Ph.D. Baltimore, MD: Johns Hopkins University Press.

NSF, NIH, USED, USDA, NEH, \& NASA. (2009). Survey of earned doctorates. Retrieved from: http://www.nsf.gov/statistics/srvydoctorates/.

Pascarella, E. T., \& Terenzini, P. T. (1991). How college affects students: Findings from twenty years of research. San Francisco, CA: Jossey-Bass.

Patton, M. Q. (2002). Qualitative evaluation and research methods (3rd ed.). Thousand Oaks, CA: Sage.

Peters, D. L., \& Daly, S. R. (2011). The challenge of returning: Transitioning from an engineering career to graduate school. Proceedings of the American Society of Engineering Education Annual Conference E Exposition, Vancouver, BC.

Peters, D. L., \& Daly, S. R. (2012). Why do professionals return to school for graduate degrees? Proceedings of the American Society of Engineering Education Annual Conference E Exposition, San Antonio, TX.

Prusak, Z. (1999). Learning environment in engineering technology with a high percentage of non-traditional students. Proceedings of the American Society of Engineering Education Annual Conference E' Exposition, Charlotte, NC.

Purdy, C., \& Washburn, M. (2005). Diversity in engineering education - What are the perceived issues? Proceedings of the American Society for Engineering Education Annual Conference Eं Exposition, Portland, OR.

Richard, O. C., \& Shelor, M. (2002). Linking top management team heterogeneity to firm performance: Juxtaposing two mid-range theories. International Journal of Human Resource Management, 13(6), 958-974. 
Richardson, J. T. E., \& King, E. (1998). Adult students in higher education: Burden or boon? Journal of Higher Education, 69(1), 65-88.

Ryan, G. W., \& Bernard, H. R. (2003). Techniques to identify themes. Field Methods, 15(1), 85-109.

Schilling, W. (2008). Issues effecting [sic] doctoral students returning to engineering education following extensive industrial experience. Proceedings of the American Society for Engineering Education Annual Conference E' Exposition, Pittsburgh, PA.

Selby, C. C. (Ed.). (1999). Women in science and engineering: Choices for success. New York, NY: The New York Academy of Sciences.

Seymour, E., \& Hewitt, N. (1997). Talking about leaving. Boulder, CO: Westview Press.

Strutz, M. L., Cawthorne Jr., J. E., Ferguson, D. M, Carnes, M.T., \& Ohland, M. W. (2011). Returning students in engineering education: Making a case for "experience capital." Proceedings of the American Society of Engineering Education Annual Conference E Exposition, Vancouver, BC.

Thomas, D. (2006). A general inductive approach for analyzing qualitative evaluation data. American Journal of Evaluation, 27, 237-246.

University of Michigan. (2011). [Graduate student population]. Unpublished raw data.

Van Note Chism, N., Douglas, E., \& Hilson Jr., W. J. (2008). Qualitative research basics: A guide for engineering educators. Available from: http://cleerhub.org/resources/8.

Walker, G. E., Golde, C. M., Jones, L., Bueschel, A. C., \& Hutchings, P. (2008). The formation of scholars: Rethinking doctoral education for the twenty-first century. San Francisco, CA: Jossey-Bass.

Wigfield, A., \& Cambria, J. M. (2010). Expectancy-value theory: Retrospective and prospective. In S. Karabenick \& T. Urdan (Eds.), Advances in motivation and achievement (Vol. 16). Bingley, United Kingdom: Emerald Group.

Wigfield, A., \& Eccles, J. (2000). Expectancy-value theory of achievement motivation. Contemporary Educational Psychology, 25, 68-81.

\section{Authors}

Diane L. Peters is a senior control systems engineer at LMS North America, 5755 New King Court, Troy, Michigan, 48098; diane.peters@sbcglobal.com.

Shanna R. Daly is an assistant research scientist in engineering education at the University of Michigan, 210 Gorguze Family Laboratory, 2609 Draper Road, Ann Arbor, Michigan, 48104; srdaly@umich.edu. 